\title{
EaD E O DILEMA DA EXPERIMENTAÇÃO NA FORMAÇÃO DE PROFESSORES DE QUÍMICA: APORTES SOBRE O TRADICIONAL E AS NOVAS TECNOLOGIAS DIGITAIS NAS ATIVIDADES LABORATORIAIS
}

\section{INTRODUÇÃO}

As tecnologias digitais, em especial aquelas da informação e comunicação (TDIC), têm provocado grandes alterações nas mais diversas esferas da sociedade contemporânea, modificando profundamente não só o formato pelo qual historicamente as relações sociais se estabeleceram, mas também lançando novos paradigmas para que estas relações se desenvolvam futuramente ${ }^{1}$. Essas tecnologias têm sido responsáveis pela formação de uma nova estrutura cultural e social, interferindo em nossos modos de ação, nas relações sociais e nas formas de aquisição de conhecimentos ${ }^{2}$. E, em se tratando de relações sociais com vistas à produção do conhecimento, a escola permanece ainda como o espaço institucionalizado e responsável por tal tarefa. Em função disso, o impacto das TDIC despertam ainda muitas dúvidas sobre como pode ser a relação entre tecnologias e educação, pois, temas importantes como: a formação dos professores articulados à sociedade cibercultural; as competências necessárias aos alunos/cidadãos; as novas metodologias; os recursos didáticos cada vez mais on-line, etc, demandam reflexões profundas e mudanças importantes na própria concepção de sistema educacional. Sendo assim, é necessário pensar em um modelo de formação profissional que possibilite integrar efetivamente estas novas competências, tornando-os aptos a produzirem e utilizarem as potencialidades das TDIC de forma crítica ${ }^{2}$. Nesse cenário ganham destaque as modalidades de formação de professores à distância (EaD). Fundamentando-se na autonomia dos discentes, a formação a distância integra as TDIC à sua proposta pedagógica, o que nos leva a crer que os professores formados nessa modalidade estarão mais bem preparados a lidar com essa temática de forma crítica, criativa e competente em suas práticas pedagógicas ${ }^{3}$. Dentre os diversos cursos criados nas últimas décadas, aqueles que, tradicionalmente, são pautados em aulas experimentais 
têm sido alvo de intensos debates. Dentre os cursos oferecidos na modalidade semipresencial no Brasil, a Pedagogia, por exemplo, apresenta quase 300 mil matriculas de graduação, enquanto os cursos de formação de professores de química não atinge $4.000 \mathrm{mil}^{4}$. Além de ser um reflexo do mercado e da educação do século XXI, a ampliação da oferta de cursos de formação de professores em química na modalidade $\mathrm{EaD}$ representa, também, uma resposta à falta destes professores estimada em mais de 23 mil docentes ${ }^{5}$. Pensar a formação em EaD do docente em química implica, portanto, identificar modos de viabilizar essa formação considerando a manutenção da natureza dessa ciência que, historicamente, congrega grande importância ao desenvolvimento de habilidades práticas. A dificuldade, portanto, em conciliar atividades experimentais com 0 formato dos cursos a distância é muitas vezes apontada como obstáculo central na proposição de graduação em química nessa modalidade de ensino. $O$ desenvolvimento de atividades experimentais em espaços não laboratoriais, desprovidos de supervisores ou de uma proposta pedagógica clara pode levar ao entendimento de que o aluno deixaria de adquirir habilidades técnicas básicas exigidas de um curso em química ${ }^{6}$. Neste sentido, a atividade laboratorial presencial é tida como imprescindível, embora esteja disponível hoje uma ampla diversidade de tecnologias digitais desenvolvidas para a mitigação do dilema das atividades laboratoriais nos processos a distância de ensino/aprendizagem de química. Com tal problemática este trabalho trata da relação entre experimentação e formação de professores de química na modalidade semipresencial e na perspectiva da EaD. A partir de um estudo teórico bibliográfico acerca das principais vantagens e desvantagens das três principais modalidades de laboratórios possíveis de implantação: remotos, virtuais e presenciais, discute-se as principais características de cada formato, expondo suas potencialidades para o ensino de química e os desafios para implantação.

\section{LABORATÓRIO PRESENCIAL (LP)}

Nos laboratórios convencionais, duas características são normalmente destacadas: (1) a necessidade de equipar um determinado espaço físico para a realização de experimentos e (2) os alunos devem permanecer durante todo o processo presentes neste espaço. Há argumentos recorrentes ${ }^{7-8}$ de que somente 
nestes espaços pode-se experienciar o contato real com os dados laboratoriais e são nestas oportunidades que ocorrem divergências entre teoria e dados experimentais que auxiliariam os estudantes a entender 0 papel da experimentação em sua formação. Apesar de serem descritos pelos autores como sendo espaços onerosos que demandam esforço para manutenção e investimento em pessoal qualificado, no Brasil e no mundo, essa é a modalidade que tem proporcionado a edificação da ciência química.

\section{LABORATÓRIO REMOTO (LR)}

São similares aos LP, necessitando de espaço físico e equipamentos, porém podem ser acessados de qualquer local com auxílio de um computador conectado à Internet ${ }^{9}$. Através da Internet $\mathrm{o}$ aluno pode buscar detalhes dos experimentos a serem realizados e enviar remotamente comandos para que sejam executados. As vantagens dos LR são fornecer dados reais de experimentos, que podem ser utilizados por uma série de usuários remotamente, ampliando a capacidade de um laboratório convencional e também a possibilidade do aluno executar diversas vezes um determinado experimento ${ }^{7}$. Os LR viabilizam a aprendizagem autônoma, otimizam a operacionalidade destes espaços e são compatíveis com a idealização de cursos a distância ao inserir o aluno em um contexto real da realização do experimento. A contínua manutenção dos hardwares e os problemas de comunição que eventualmente podem ocorrer são citados como as principais desvantagens dos $\mathrm{LR}^{9}$ na implantação em cursos EaD.

\section{LABORATÓRIO VIRTUAL (LV)}

Constituem-se de softwares que simulam as atividades de laboratórios reais. Mais comuns e com maior gama de apresentações, essas ferramentas atualmente abarcam uma considerável parcela dos conteúdos experimentais normalmente pertencentes aos currículos da formação em química. Os LV são opções bastante eficientes como atividades pré-laboratórios em cursos presenciais, como também representam uma possibilidade bastante eficiente aos cursos à distância ${ }^{10}$. Há outras vantagens como possibilitar a) a realização de experiências simuladas que não seriam executas em função dos altos custos ou da manipulação de produtos perigosos b) a reprodução irrestrita das experiências pelos alunos ao refazerem 
os experimentos fora da sala de aula c) a realização de trabalhos individuas, em grupos colaborativos com funções que as próprias ferramentas disponibilizam ${ }^{11}$. Entretanto, esse tipo de aplicação "é totalmente baseado em simulações, dispondo somente de representações computacionais da realidade"12 (p. 3). Sua utilização impossibilita o aluno de manter interação com equipamentos reais, cujos dados obtidos em experimentações virtuais são idealizados e normalmente realizados sem supervisão.

\section{CONCLUSÃO}

À guisa de conclusão, observa-se o desenvolvimento de interfaces digitais compatíveis com tecnologias mobile como smartphone e tablets aptas a complementar as atividades laboratoriais presenciais no ensino de química. E, pelas potencialidades que apresenta e pela emergência de novas formas de aprender, as TDICs representam para a formação de professores de química a possibilidade de quebra de paradigmas importantes de uma ciência consolidada e fundada no espaço do laboratório, imortalizado por suas vidrarias, reagentes, linguagem (muitas vezes hermética) e procedimentos operacionais, atitudinais e conceituais específicos. Em todos os modelos de laboratórios disponíveis, evidenciam-se vantagens e desafios à sua aplicabilidade em qualquer modalidade de ensino. Nesse sentido, a utilização balanceada das múltiplas formas virtuais e presenciais de aprender - e não somente na exclusividade desta última - talvez seja um caminho promissor à superação do dilema da experimentação na formação a distância de professores de química.

\section{REFERÊNCIAS}

1 GABRIEL, Martha. Educ@ r: a (r) evolução digital na educação. São Paulo: Saraiva, 2013. $241 \mathrm{p}$

2 KENSKI, V. M.. Tecnologias e ensino presencial e a distância. 2. ed. Campinas: Papirus,2004. (Série Pratica Pedagógica).

3 BELLONI, M. L. Mídia-educação e Educação a distânicia na formação do professores. In: MILL, D.; PIMENTEL, N. (Orgs.). Educação a Distância: desafios contemporâneos. São Carlos: EdUFSCar, p. 245-265, 2010 
4 INEP. Instituto Nacional de Estudos e Pesquisas Educacionais Anísio Teixeira Sinopse Estatística do Ensino Superior: 2013. Brasília: MEC/INEP/DEED, 2013. Disponível em: < http://portal.inep.gov.br/superior-censosuperior-sinopse >. Acesso em 24/10/2015.

5 MOTTA, C. S.; GALIAZZI, M. C. Um panorama sobre as Licenciaturas em Química na modalidade EaD vinculadas ao SisUAB . In: Encontro de Debates sobre o Ensino de Química, 33., 2013, Ijuí. Anais do .... Ijuí: Unijuí, 2013.

6 CASANOVA, R. S. et al. Distance Learning: A Viable Alternative to the Conventional Lecture-Lab Format in General Chemistry. ournal of Chemical Education, v. 83, n. 3, p. 501, 2006.

7 YASSER, Elawady; TOLBA, Ahmad. Educational objectives of different laboratory types: a comparative study. Int. J. Computer Sci. Inform. Security , v. 6, n. 2, p. 89-96, 2009.

8 MA, Jing; NICKERSON, Jeffrey V. Hands-on, simulated, and remote laboratories: A comparative literature review. ACM Computing Surveys, v. 38, n. 3, 2006.

9 TAKAHASHI, Eduardo Kojy; CARDOSO, Dayane Carvalho. Experimentação Remota em Atividades de Ensino Formal: um Estudo a Partir de Periódicos Qualis A. Revista Brasileira de Pesquisa em Educação em Ciências, v. 11, n. 3, p. 185-208, 2012.

10 BOTTENTUIT JUNIOR, J. B. et al. Análise da Usabilidade de um Laboratório Virtual de Química Orgânica. In; Conferencia Ibero-americana em Sistemas, Cibernética e Informática, 6., 2007. Anais do... Orlando, 2007

11 CATALDI, Z. et. al. Didáctica de la química y TICs: Laboratorios virtuales, modelos y simulaciones. In: Congreso de Tecnología en Educación y Educación en Tecnología, 4., 2009. Anais Eletrônicos... La Plata, 2009.

12 SCHMITT, Marcelo Augusto Rauh; TAROUCO, Liane Margarida Rockenbach. Metaversos e laboratórios virtuais-possibilidades e dificuldades. RENOTE, v. 6, n. 2, 2008. 